Portland State University

PDXScholar

11-7-1995

\title{
Effects of Receptive Language Deficits on Persisting Expressive Language Delays
}

Traci Lee Giacherro

Portland State University

Follow this and additional works at: https://pdxscholar.library.pdx.edu/open_access_etds

Part of the Speech and Rhetorical Studies Commons

Let us know how access to this document benefits you.

\section{Recommended Citation}

Giacherro, Traci Lee, "Effects of Receptive Language Deficits on Persisting Expressive Language Delays" (1995). Dissertations and Theses. Paper 4949.

https://doi.org/10.15760/etd.6825

This Thesis is brought to you for free and open access. It has been accepted for inclusion in Dissertations and Theses by an authorized administrator of PDXScholar. Please contact us if we can make this document more accessible: pdxscholar@pdx.edu. 


\section{THESIS APPROVAL}

The abstract and thesis of Traci Lee Giacchero for the Master of Science in Speech Communication: Speech and Hearing Science were presented November 7, 1995, and accepted by the thesis committee and the department. COMMITTEE APPROVALS

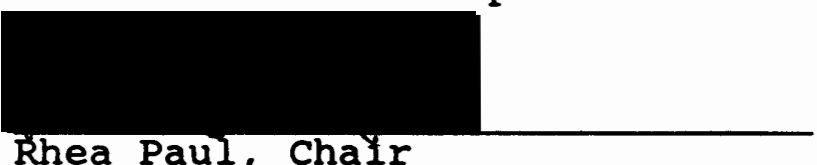

Rhea Paul, Chair
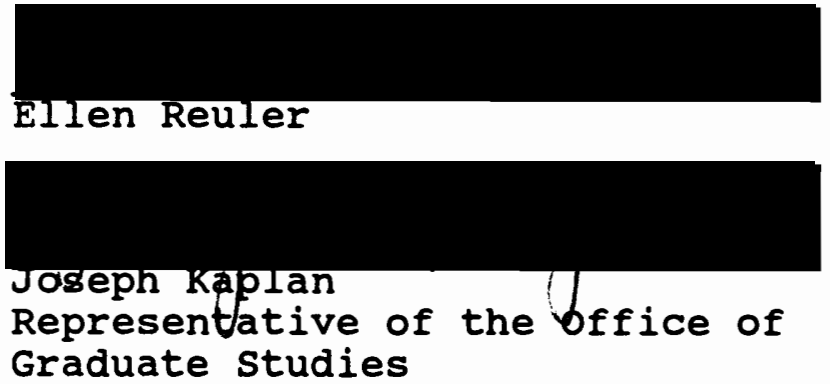

DEPARTMENT APPROVAL:

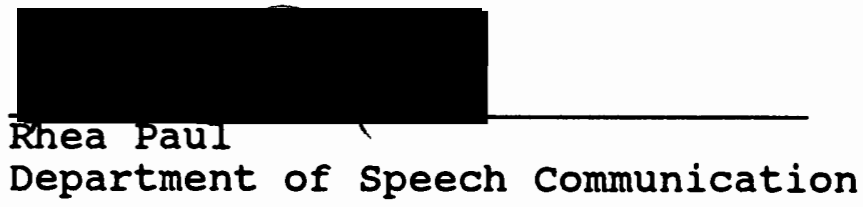

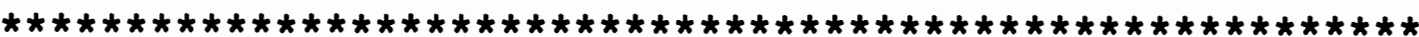
ACCEPTED FOR PORTLAND STATE UNIVERSITY BY THE LIBRARY by on 19 dec 1995 


\section{ABSTRACT}

An abstract of the thesis of Traci Lee Giacchero for the Master of Science in Speech Communication: Speech and Hearing Science presented November 7, 1995.

Title: Effects of Receptive Language Deficits on Persisting Expressive Language Delays.

Predicting language outcomes in children who at age two are "late talkers" is a concern of Speech Language Pathologists. Currently, there is no conclusive data allowing specialists to predict which children will outgrow their delays and which children will not. The purpose of the present study is to analyze the effect of a receptive language delay on the outcome of the slow expressive language delayed child, and determine whether or not it is a viable predictor of poor outcomes.

The subject information used in this project was compiled from the data collected and reported by Paul (1991) during the Portland Language Development Project (PLDP). Children in the PLDP first participated in the longitudinal study between the ages of twenty to thirtyfour months. They were categorized as being slow in expressive language development if they produced fewer 
that fifty intelligible words during this age range. They were then subgrouped into an expressive-receptive delayed group if they scored more than one standard deviation below the mean on the Reynell Developmental Language Scales. Of the twenty-five subjects with complete data over the five years of the study, nineteen were considered to be solely expressively delayed, while the remaining six were classified as having both an expressive and a receptive language delay.

Lee's Developmental Sentence Scoring (DSS) (1974) was used to track the subject's expressive language abilities to the age of seven. DSS scores were analyzed yearly, using the Mann-Whitney nonparametric statistical test. This would determine whether the subjects considered to be both expressively and receptively delayed were exhibiting more difficulties in their expressive language abilities than those subjects with expressive delays alone.

The results of the study indicated that significant differences did not exist between the two groups. Therefore, there was insufficient evidence to conclude that a receptive language delay at twenty to thirty-four months of age is a feasible predictor of lasting expressive language delays. This leads to the recommendation that additional research be conducted focusing on areas other than receptive language abilities as being predictors of poor expressive language outcomes. 
EFFECTS OF RECEPTIVE LANGUAGE DEFICITS

ON PERSISTING EXPRESSIVE LANGUAGE DELAYS

by

TRACI LEE GIACCHERO

A thesis submitted in partial fulfillment of the requirements for the degree of

MASTERS OF SCIENCE in

SPEECH COMMUNICATION :

SPEECH AND HEARING SCIENCE

Portland State University

1995 


\section{ACKNOWLEDGEMENTS}

I wish to thank Dr. Rhea Paul for guiding and supporting me with expert advice in this project.

I would also like to thank Joan McMahon who participated early on as a member of my thesis committee, and Ellen Reuler who so willingly agreed to complete this process in lieu of Joan's retirement.

A special thanks goes to my mom and dad, Ken and Connie Giacchero, who offered their assistance during the past two years of graduate school. I feel very thankful for the constant support and encouragement they gave me during this project.

Finally, my sister and brother-in-law, Theresa and Scott wilson, need special recognition; for without them, the original version of this project may have never got off the ground. 
TABLE OF CONTENTS

PAGE

ACKNOWLEDGEMENTS . . . . . . . . . . . . . . . . iii

LIST OF TABLES . . . . . . . . . . . . . . . . . . vii

CHAPTER

I INTRODUCTION AND STATEMENT OF PURPOSE . . 1

Introduction . . . . . . . . . . . 1

Statement of Purpose. . . . . . 2

The Research Hypothesis . . . 2

The Null Hypothesis . . . . . 3

Definition of Terms . . . . . . . 3

I REVIEW OF THE IITERATURE . . . . . . . 5

Outcomes of SII . . . . . . . . . 6

Outcomes in Late Talkers . . . . 8

Predictors of Outcome . . . . . . 9

Debate over Subtyping and Outcome . 12

III METHODS AND PROCEDURES . . . . . . . . 17

Subjects . . . . . . . . . . . . 17

Subject Description at Intake:

20 to 30 Months...... . 17

Procedures. . . . . . . . . . 18

Instrumentation . . . . . . . . 21

Reynell Developmental Language Scales . . . . . . . . 21

RDIS Reliability 
PAGE

Developmental Sentence scoring 23 DSS Reliability

Data Analysis . . . . . . . . 25

IV RESULTS AND DISCUSSION . . . . . . . 27

Results . . . . . . . . . . 27

Discussion . . . . . . . . 30

Insignificant Sample Size . . 31

High Cutoff Score for Determining

Receptive Language Delays . . 31

Receptive Language as a Predictor

of Language Abilities . . . 32

$\mathrm{V}$ SUMMARY AND IMPLICATIONS . . . . . . . 33

Summary . . . . . . . . . . 33

Implications . . . . . . . . . 34

Clinical Implications . . . 34

Counseling for parents

Preventative treatment

programs

Methods used in treating

a client

Research Implications . . . 35

REFERENCES . . . . . . . . . . . . . . . . . 37

APPENDICES
A
HUMAN SUBJECTS APPROVAL . . . . . . 41
B
RAW DATA FROM DSS . . . . . . 43
C
REYNELL DEVELOPMENTAL IANGUAGE SCALE 45
D
REYNELI DEVELOPMENTAL LANGUAGE SCALE
STANDARD SCORES . . . . . . . 49 
PAGE

E

DEVELOPMENTAL SENTENCE SCORE . . . 51

F DEVELOPMENTAL SENTENCE SCORE NORMS. 55 


\section{LIST OF TABLES}

TABLE

PAGE

I Summary of Demographic Data . . . . . . . 19

II DSS Mean Rank Scores. . . . . . . . . . 28

III Summary of Mann Whitney Sum of Ranks Test . 29

IV Percentage of Subjects Considered to be Within Normal Range on the DSS . . . . . 30 
CHAPTER I

INTRODUCTION AND STATEMENT OF PURPOSE

INTRODUCTION

Predicting language outcomes in children who, at age two, have slow expressive language development has long been a concern of speech language pathologists (SLPS). Currently, there are no conclusive data supporting differentiating prognoses for late talking toddlers, and parents are often told their children will outgrow their language delay. In many cases, this may be true; however, there remains a percentage of children with slow expressive development whose problems persist throughout their preschool years, resulting in learning disabilities at school age. This leads to the all encompassing question: which children will grow out of their delay and which will continue to have problems?

The research reported in this thesis is not an attempt to answer this broad question, but rather takes a small piece of the puzzle: receptive language delays, and analyzes its effect on the slow expressive language delayed child (SELD)

There may be many potential advantages to finding predictive measures of language outcome in these late 
talking toddlers. If parents, physicians, and SLPs are aware of a potential problem, treatment can be started at a much younger age than if the parents were to wait two or three more years before beginning intervention. Speechlanguage pathologists can counsel the parents about the risks involved when expressive language is delayed. If predictive measures can be offered as evidence for possible continued delay, early treatment can be started as a preventative measure.

\section{STATEMENT OF PURPOSE}

The purpose of this study is to determine whether receptive language deficits in children with SELD at the age of two years may have a possible lasting effect on the expressive language abilities in the school age child. This research will focus on the outcomes in expressively delayed children versus children with both expressive and receptive language deficits.

The research hypothesis

The research hypothesis for this study is that children at twenty to thirty-four months of age with delays in both receptive and expressive language, will have a significantly higher risk of having expressive language deficits at school age, than children with expressive delays alone, at twenty to thirty-four months. 
The nul1 hypothesis

Thus the null hypothesis states that children at twenty to thirty-four months of age who have concurrent receptive and expressive language delays are not at a significantly higher risk of having expressive language deficits at school age, than children with expressive delays only, at twenty to thirty-four months.

\section{DEFINITION OF TERMS}

Port land Language Development Project (PLDP): A longitudinal study researching the outcomes of Late Talkers (LT) .

Specific Language Impairment (SLI): SLI is considered to be a relatively specific failure of normal language functions, in the absence of any neurological damage (Tallal, 1988).

Late Talkers (LT): Subjects categorized by the PLDP to have vocabularies less than fifty different words at the age of twenty to thirty-four months, in accordance with the Rescorla (1989) Language Developmental Survey (IDS).

Slow Expressive Language Delay (SELD): Subjects categorized by the PLDP to have vocabularies less than fifty different words at the age of twenty to thirty four months, in accordance with the Rescorla (1989) Language Developmental Survey (LDS) .

Receptive/Expressive Lanquage Delay: Subjects categorized by the PLDP to have vocabularies of less than 
fifty different words at twenty to thirty-four months of age, according to the LDS; as well as, score one standard deviation or more below the mean on the comprehension skills section of the Reynell Developmental Language Scales (RDLS). Reynell Developmental Language Scales (RDLS):

Standardized assessment, used to measuring the development of verbal comprehension at intake in the PLDP (Reynell, $1983)$

Developmental Sentence Scoring (DSS): Standardized measure of syntactical development in children, based on a spontaneous language sample (Lee, 1974). 
CHAPTER II

REVIEW OF THE LITERATURE

One of the many problems facing Speech Language Pathologists today is the prediction of outcomes in toddlers with slow expressive language development. For many years it had been assumed that children who were late talkers would naturally grow out of their deficits. However, according to Paul (1991), very little is known about the prognosis for two year olds with delayed expressive language abilities. Thus, there is a danger of misdiagnosing normal toddlers as language-impaired and impaired children as normal (Thal \& Tobias 1994).

Should clinicians adopt a wait and see attitude with children, or should all late talkers be placed in early intervention? Both extremes seem unrealistic, since research has shown that although many children will outgrow their expressive delay, a certain percentage will not (Thal \& Tobias, 1994; Paul, Spangle Looney, \& Dahm, 1991; Rescorla \& Schwartz, 1990; Scarborough \& Dobrich, 1990; Thal, Tobias, \& Morrison, 1991). A significant proportion of toddlers identified as delayed in expressive language development between eighteen and thirty-two months of age remain delayed, and are at a high risk for further language disorders, social emotional problems, and learning 
disabilities (Thal \& Tobias, 1994; Rutter, Mahwood, \& Howlin, 1992; Paul, Spangle Looney, \& Dahm, 1991; Rescorla \& Schwartz, 1990; Scarborough \& Dobrich, 1990; Thal, Tobias, \& Morrison, 1991).

Since the ability to predict outcomes in late talkers is limited, work continues in studying the language factors associated with outcomes. It is crucial to identify those children with specific Language Impairment (SII) deficits before language and learning disabilities are exhibited at school age.

\section{OUTCOMES OF SLI}

As stated previously, research has indicated that some preschoolers with SII have chronic deficits. Deficits, as indicated by Scarborough and Dobrich (1990), can manifest themselves not only in language disabilities, but also in learning disabilities. These learning disorders include: reading, phonological, and pragmatic difficulties (Whitehurst, Fischel, Lonigan, Valdez-Menchaca, Arnold, and Smith (1991).

Aram and Nation (1980) demonstrated the risk for chronic language and learning deficits in SLI children. They stated that levels of language comprehension and expression of children in preschool are correlated to speech, language, and academic abilities at school age. In their longitudinal study of 63 language disordered children, evaluated in preschool, and followed four to five years 
after their initial diagnosis, $40 \%$ of the children continued to have speech and language problems and $40 \%$ continued to have other learning disabilities.

Haynes and Naidoo (1991) also agree, that as evidenced by research, preschoolers diagnosed with SLI usually have poor prognoses in the areas of language and learning. They stated that the production of language depends upon the possession and coordination of a number of converging skills. In their study, the most disabled children expressively were likely to be disabled in every expressive function as well as receptive language and cognitive functioning: inadequate vocabulary; limited sentence structure; and general impoverishment of content. They contend that when school age children are left to combine expressive deficits with problems in receptive language, listening skills, memory, grammar, etc., the outcome is poor.

Consistent with these findings, Scarborough and Dobrich (1990) also found poor outcomes when they followed four preschoolers with SLI through the age of seven. They concluded that the fairly severe deficits the children exhibited in the areas of syntax, phonology, and lexical semantics gave way to more "selective impairments," such as in reading.

In summary, researchers have documented persistent deficits in the areas of language and learning in children 
who are labeled in their preschool years as being specific language impaired. These findings have provided an incentive to find a reliable means of predicting which children will eventually be labeled SLI. Therefore, in lieu of the concern for preventative measures in speech-language pathology, the focus of recent research has shifted from studying the documented disorders in SII children, to studies of younger children who are considered to be late talkers. This suggests that such children may also be at risk for long-term problems (Locke, 1994; Thal \& Tobias, 1994; Thal, Tobias, \& Morrison, 1991). OUTCOMES IN LATE TALKERS

"Late Talkers," as they are referred to in the literature are children who are younger than four years of age who are slow in expressive language development. Between the ages of two and three, children are considered to be too young for the formal diagnoses of Specific Language Impaired. However, many of these children will eventually become labeled as SLI as they reach four and five years of age.

Several longitudinal studies (Paul, Spangle Looney, \& Dahm, 1991; Whitehurst et al., 1991; Rescorla \& Schwartz, 1990; Scarborough \& Dobrich, 1990; Bishop \& Edmondson, 1987) have looked at these Late Talkers and indicated that even though approximately fifty percent of the chilaren slow in expressive language development (SELD) may appear to recover 
in terms of linguistic performance by age three, some learning disorders in the areas of reading, spelling, and writing may appear in these children later on. A study on outcomes in children who have persistent expressive deficits (Paul, Laszlo, McFarland, \& Midford, 1992), found lasting deficits in expressive language as well as in reading readiness and narrative ability. These findings suggest that children with persistent expressive deficits are at a risk for academic difficulty when they reach school age. Rescorla and Schwartz (1990) in their study of outcomes in toddlers with expressive language delay, stated that there was a strong relationship between the severity of the initial disorder and its outcome. Thus, many researchers of Late Talkers (LT) have investigated the factors, or disorders, found in combination with the early expressive delay that may relate to the severity and serve as predictors of outcome.

\section{PREDICTORS OF OUTCOME}

The ability to predict outcomes in Late Talkers would be the first step in being able to provide preventative treatment for SELD children; however, identifying the factors which would serve as predictors has proven to be difficult. Schery's (1985) study indicated, that although a number of factors such as age, IQ, SES, language history, and social/emotional status account for small portions of the variances among the language disordered children, 75\% of 
the variances in her study were attributed to unknown factors. Therefore, several deficits which have occurred simultaneously with expressive language delay are now regarded as increasing the severity of, and having possible effects on, later language abilities of late talkers.

As stated previously, Aram and Nation's 1980 study of preschool children's levels of receptive language, sentence formulation, semantics, syntax, phonology, and speech production, found all of these factors to be moderately correlated to future speech, language, and academic performance in school. Haynes et al. (1991) support Aram and Nation's study, and contend that when delays in expressive skills are combined with other deficits in the areas of receptive language, listening skills, memory, and grammar, future persistent problems can be expected.

Other studies (Thal \& Tobias, 1994; Thal, Tobias, \& Morrison, 1991; Paul, Spangle-Looney, \& Dahm, 1991; Bishop \& Edmondson, 1987; Paul \& Smith, 1987) have looked at particular concomitant deficits with an expressive language delay. Factors such as semantic ability, or story telling, socialization skills, and receptive deficits were studied as possibly having a more predictive nature than other factors in terms of outcomes.

Bishop and Edmondson (1987) in their study on predicting language outcomes of children with phonological, syntactic, morphology, semantic, and/or receptive language 
delays, reported that phonological impairment at four years of age is the only speech or language measure which does not differentiate children with a good or bad outcome. They suggested that measures of expressive semantic ability, such as simple story telling or narrative skills, are strongly related to language outcomes.

Paul and Smith (1993) in their study of 28 late talking toddlers, also found that there were significant deficits in narrative skills. Finally, as indicated by Bishop and Edmondson (1987), narrative skills in young children have been shown to be one of the best indicators of future academic success in school.

other studies have looked at gestures and receptive capabilities as having an adverse effect on outcome. In 1991, Thal, Tobias, and Morrison did a study on language and gestures in late talkers, they found that vocabulary comprehension predicted later delay in production. Vocabulary comprehension in this study correlated language comprehension with the production of symbolic gestures; thus, a delay in the comprehension and production of gestures was attributed to lasting expressive language delays. In 1994, Thal and Tobias replicated the 1991 Thal, Tobias, and Morrison study, and once again found that vocabulary comprehension reflects the underlying cognitive abilities shared with gesture production. Therefore, the more impaired the comprehension abilities of the children, 
the less diversified they were in their expressive symbolic productions. Another study which included the factor of receptive language in continuing expressive deficits was conducted by Paul, Spangle Looney, and Dahm (1991), in which both receptive delays and socialization skills were considered. The data from this study indicate that neither a deficit in socialization skills or in receptive language abilities was considered to be a major factor in the continuance of a delay in a SELD child from the ages of two to three. However, further studies of these and other factors were suggested.

studying the factors which may be associated with longterm deficits in language and learning, has led to the idea of subtyping children into categories based on the problems they display. Currently there is a debate over differential diagnosis and prognoses of outcomes in children who have been categorized into one subgrouping or another. DEBATE OVER SUBTYPING AND OUTCOME

Many of the early authors classified children with developmental language disorders into subgroups according to their presumed etiological background (Aram \& Nation, 1975). More recently, a concerted effort has be made to classify types of language disorders based on the language behaviors themselves, when no etiological basis can be found (American Psychiatric Association, 1994; Tallal, 1988; Wolfus, Moscovitch, \& Kinsbourne, 1980; Aram et al., 1975). These 
are the subgroupings which researchers have determined to be most relevant when working with children with SLI.

In 1988, Tallal investigated in detail the

relationship between receptive and expressive language development and the stability of subdivisions in these areas over time. She recognized three subgroups that are often used in the literature with SLI children. They include: (a) children who comprehend significantly more than they produce (expressively delayed), (b) children who speak remarkably well in comparison to their performance on tests of comprehension (receptively impaired), and (c) children who are significantly impaired in both areas (concomitant receptive-expressive delays). Two of these subdivisions have also been recognized and incorporated by the American Psychiatric Association (1994), into their Diagnostic and Statistical Manual IV (DSM-IV). These categories of SLI, as Iisted in the DSM-IV include: (a) Expressive language disorder, and (b) Mixed receptive-expressive disorder. In the past, diagnostic differentiations in the areas of expressive language and receptive language have been found to be clinically meaningful to speech-language pathologists. Authors like Rapin (1988) feel that when subtyping is based on an analysis of the children's language disabilities, educationally relevant subgroupings occur. Rapin believes there is a higher probability of learning disorders in those children with concurrent expressive- 
receptive delays. Aram (1988) also supports the use of subtyping for diagnosis and treatment. She admits that even though there is controversy over subtypes and their stability overtime, studies such as Bishop and Edmondson (1987), have demonstrated the persistence of SLI subtypes; thus validating their use clinically. Such diagnostic differences in the areas of expressive and receptive language may determine whether recovery or persistence will ensue for particular children (Scarborough et al., 1990). In opposition to the subtypes, Tallal (1988), has found that the different subtypes do not differentiate greatly in terms of outcomes, when linguistic skills are measured by standardized tests. Therefore, Tallal concluded that all SLI children must fall into one homogeneous group, and that subtyping children based on linguistic performance is not always relevant, especially in terms of intervention. She does agree it still may be important prognostically, as the probability of later learning disability is higher in receptively than expressively impaired children (Rapin, 1988; Bishop \& Edmondson, 1987; Aram \& Nation, 1975).

In light of this disagreement in the literature, it seems reasonable to ask whether children with a receptive component added to their expressive delay, should be considered a greater risk for developing later language and learning disabilities. Studies such as Paul et al. (1991) indicate this is not a possibility. As stated earlier, her 
study indicated that receptive language abilities were not significant factors in the outcomes of children from ages two to three. Whitehurst et al. (1991) writes that receptive language is not to be a determinant variable in the expressive delay dilemma, since both expressive and receptive language develop independently, and are functions of different sets of biological and environmental factors. Thal et al. (1994) on the other hand, reported that children with limited symbolic gestures as a result of receptive language delays, had a later delay in expressive language; thus stating that early comprehension abilities can predict later delays in production ability. All of the authors cited admit that receptive language studies are scarce, and more studies should be considered.

These conflicting findings of studies on the receptive language abilities in young children make it difficult to determine whether receptive skills or any linguistic factor can reliably predict outcome in SELD children. Therefore, should subtypes be based on a linguistic factor such as comprehension skills which may or may not affect later language and learning deficits? This question continues to be debated in current research (Locke, 1994).

Due to the contrasting and inconclusive evidence in this area, the current study will attempt to identify the expressive language outcomes in SELD children in the subtypes of expressive and receptive-expressive delays over 
a five year period. This researcher hopes that the present study will shed more light on the controversy regarding receptive language delays as having a negative effect upon late talkers' expressive abilities at school age, and the use of linguistic subtypes for children diagnosed with SLI. 
CHAPTER III

METHODS AND PROCEDURES

SUBJECTS

The subject information used in this project was compiled from the data collected and reported by Paul (1991) during the Portland Language Development Project (PLDP). Paul began her longitudinal study of toddlers with slow expressive language development in 1987 and it continues to the present. Data was retrieved from the files of the study's participants and categorized according to children with expressive delay and children with concurrent receptive deficits.

SUBJECT DESCRIPTION AT INTAKE: 20 TO 34 MONTHS

Children in the PLDP first participated in the project between the ages of twenty to thirty-four months. They were categorized as being slow in expressive language if they produced fewer than fifty intelligible words during this age range. Children meeting this criterion were selected by the means of questionnaires distributed to the offices of pediatricians, and through radio and newspaper advertising. The potential subjects' parents were then given Rescorla's (1989) Language Development Survey, a parent checklist which consists of 300 of the most common words used by children. This was the initial determination 
of slow expressive language development. All thirty-seven subjects chosen passed a hearing screening, had IQs on the Bayley Scale of Infant Development (Bayley, 1969) above 85, and passed an informal screening for neurological disorders and autism. Of the thirty-seven children, $73 \%$ were males, and $27 \%$ were female. A normal contrast group was included in the original PLDP. However, only subjects classified as SELD will be included in the current study.

Table I displays the demographic information of the diagnostic groups at intake, including mean age at intake, SES, sex, and comprehension score on the Reynell Developmental Language Scale (Reynell, 1983).

PROCEDURES

This research will divide children originally diagnosed as SELD into two groups: those with delays in expressive language only and those with delays in both expressive and receptive skills, at entrance into the study. Progress in expressive language level will be followed for the two groups.

The Reynell Developmental Language Scales (RDLS) (Reynell, 1983) was used as the initial assessment of children, in order to subgroup the subjects and document their receptive language skills. The protocol for administering the RDLS was strictly followed in obtaining the profiles for the SELD children based on this instrument. Examiners using this scale for the PLDP, were experienced in 
TABLE I

SUMMARY OF DEMOGRAPHIC DATA

\begin{tabular}{|c|c|c|c|c|c|c|}
\hline $\begin{array}{l}\text { (SD) } \\
\text { Group }\end{array}$ & $n$ & $\begin{array}{l}\text { Mean age } \\
\text { (and sd) in } \\
\text { months at intake }\end{array}$ & $\begin{array}{l}\text { Mean SES } \\
\text { (and SD) }\end{array}$ & Race & $\operatorname{sex}$ & $\begin{array}{l}\text { RDLS } \\
\text { score }\end{array}$ \\
\hline $\begin{array}{l}\text { Expressive } \\
\text { Impairment }\end{array}$ & 27 & $24.9(3.8)$ & $3.44 *(.79)$ & $\begin{array}{r}9681 \\
480\end{array}$ & $\begin{array}{l}7487 \\
268 \mathrm{~F}\end{array}$ & $\begin{array}{l}.407 \\
(.72)\end{array}$ \\
\hline $\begin{array}{l}\text { Expressive- } \\
\text { Receptive } \\
\text { Impairment }\end{array}$ & 10 & $25.4(4.05)$ & $3.6 *(.66)$ & $\begin{array}{l}808 \\
208\end{array}$ & $\begin{array}{ll}708 & M \\
308 & F\end{array}$ & $\begin{array}{l}-1.64 \\
(.44)\end{array}$ \\
\hline
\end{tabular}

* Based on Hollingshead's four factor measure of soclal position on a scale from 1 to 5 , with 1 being the highest socioeconomic status and 5 being the lowest.

(Myers and Bean, 1968) 
the testing of young children, and were familiar with the developmental sequence of language. Scoring is based on the child's response to a request given by the examiner. Examples of correct responses are outlined in the RDLS administration manual. Partial or incorrect responses are reported as a failure. Subjects used in this study were considered to have a receptive language delay if their score on the RDLS fell more than one standard deviation below the mean.

Lee's Developmental Sentence Scoring (DSS) (1974) was used to track the children's expressive language abilities to the age of seven. DSS scores were obtained by collecting a fifteen minute language sample during a parent/child interaction. The speech sample was then transcribed and the first fifty different subject-verb utterances were scored and assigned point values. The point values were based on the eight categorical descriptions in the DSS and their corresponding developmental levels. A point was also assigned for a grammatically correct sentence. Once the score for each of the fifty utterances was obtained, the Developmental sentence score was derived by adding all the sentence scores and dividing by fifty.

After the Developmental Sentence Score was calculated, it was compared to the scores of "normal" children, by plotting the score on a profile of percentile rankings given in the DSS manual. The child is considered to be delayed if 
his/her score falls below the tenth percentile for age. INSTRUMENTATION

Reynell Developmental Language Scales (RDLS) (Reynell, 1983)

As stated previously, the thirty-seven children said to have expressive language delay, were subgrouped based on their receptive scores on the RDLS at intake into the study at twenty to thirty-four months of age. The individual subjects were placed into a receptive/expressive delayed group if their receptive scores on the Reynell fell one standard deviation or more below the mean for the age level. If the children's receptive scores were in the region above -1.0 standard deviations, they were placed into the purely expressively delayed group.

The RDLS attempts to follow the developmental course of verbal comprehension. The Verbal Comprehension Scale assesses understanding of a variety of items, including: verbal preconcepts; noun labels of objects; symbolic relationships of two named objects; relations between attributes and perceived objects; longer instructions involving negatives and attributive terms; nouns and verbs; inferential questions; and complex relationships between several concepts.

RDLS Reliability. The RDLS is a well standardized, reliable, and valid instrument, as normative data was gathered from 1318 children, ranging in age from eighteen months to seven years. In terms of reliability, a 
coefficient of discriminability was calculated for each item on the test. Only items with a high level of discrimination were used. Spearman-Brown split half reliabilities were then calculated for the scale. The reliability coefficients ranged form .80 to .96 for expressive language, and .45 to .97 for verbal comprehension. Next correlations were established between Expressive Language and Verbal Comprehension Scales through the use of Pearson correlation coefficients. This coefficient ranged from .67 at eighteen months to .32 at seven years, suggesting that with older children the different aspects of language become more specific functions.

Concurrent and prediction validity of the RDLS was established by correlating the scales with thirty-four other measures of cognitive abilities, and by performing a factor analysis. The RDLS proved to be highly correlated with the other measures of cognitive ability, and a factor analysis of the correlations provided strong evidence supporting the concurrent validity of the RDLS as a measure of language development. It was also suggested by the authors, that the validity evidence of the RDIS supports the use of the Scales as a method of tapping an underlying general mental ability as well.

Inter-scorer reliability was established for the RDLS within the PLDP. Reliability was established by having two graduate students independently rescore nine percent of the 
RDLS administered to the subjects. Reliability of the scoring was one hundred percent.

Developmental Sentence Scoring

This study will track the expressive language skills of the subjects, using the Developmental Sentence Score as an index of the production of language. The DSS is derived by scoring a fifteen minute spontaneous language sample, using the method developed by Lee (1974). The DSS requires fifty different utterances that must include a subject and a verb. It scores indefinite pronouns, personal pronouns, main verbs, secondary verbs, negatives, conjunctions, interrogative reversals, and wh-questions. The DSS assigns structures (in the above mentioned categories) point values, based on eight developmental levels. It also assigns a point value of zero or one for fully formed grammatically correct sentences to help acknowledge the forms that are not scored on the test. Points for structures and fully correct sentences are tallied, added, and divided by the number of utterances (fifty), to achieve the total DSS score. If the score falls below the tenth percentile, the child is considered to be expressively delayed. By using scores received on the DSS, comparisons of expressive language abilities can be made between the subgroups.

DSS Reliability. The DSS was chosen as the method of analyzing the expressive language abilities of the subjects for its high validity and reliability measures. The DSS 
analysis was standardized on two hundred subjects, and is appropriate for scoring expressive language abilities of children between the ages of two years to six years, eleven months.

The validity of the DSS scoring system was established using multivariate analysis of variance and univariate analysis of mean developmental scores within the DSS component categories. Therefore, it was established that as age levels increased, the scores which contended to measure spontaneous syntax and morphology usage increased significantly in accordance which each increasing age level. Also, the validity of the individual grammatical procedure categories was positively correlated with the overall DSS scores by means of Pearson product-moment correlations.

In addition to and in support of the validity measures, reliability was also established for the DSS. Internal consistency of the DSS was assessed by Cronbach's Alpha Correlation Coefficient to be .71 . The reliability coefficient increased by age level indicating increasing internal consistency for the DSS with increasing subject age. Across subjects the internal consistency was measured using the Spearman-Brown's Split-Half Reliability method. This measure also showed a progressive increase in reliability with the increasing age of the subjects. Point-to-point, inter-scorer reliability was also established for the DSS within the PLDP. The reliability of 
the scoring was obtained by having trained graduate students independently rescore ten percent of the transcripts at each level (three years old to seven years old). Reliability ranged from ninety-three to ninety-seven percent.

\section{DATA ANALYSIS}

The data analysis will determine if children at twenty to thirty-four months of age, who have concurrent receptive and expressive language delays, are at a significantly higher risk of having expressive language deficits from age three to seven, than children with expressive delays only, at twenty to thirty-four months. Since this study's distribution of scores were not matched for age, sex, SES, or race, and had limited and unequal numbers of subjects in each group, it did not did not meet the requirements for a parametric test. Therefore, a nonparametric statistical test will be used to analyze the data. Statistical analysis will determine whether the expressive abilities of each independent group will differ significantly, during each year of the follow-up, over a five year period.

For this study, the nonparametric statistic chosen is the Mann-Whitney with a statistical significance set at a probability of .05. According to Doehring (1988) the .05 level indicates that only five times in one hundred would the observed difference between groups occur by chance.

In order to use the Mann Whitney or Sum of Ranks Test, the DSS scores for both independent groups are numerically 
ranked according to the number of subjects. Although thirty-seven subjects met the initial criteria for the study, only twenty-five subjects had complete data. These twenty-five subjects will be used in the data analysis. Therefore, for each year of the study, the child will be ranked from one to twenty-five, based on his/her score on the DSS. The probability of a difference between groups is then based on a difference between the sum of the ranks for each of the two groups. (See Table II). The sum of ranks reflects both the central tendency and the variability of the two distributions.

A significant difference according to the Mann Whitney would result in the null hypothesis being rejected; therefore, it would be concluded that the effect of the independent variable (receptive language abilities) has been demonstrated. The opposite will hold true for the nonsignificant Mann Whitney ratio. 
CHAPTER IV

\section{RESULTS AND DISCUSSION}

RESULTS

The purpose of this study was to determine whether children with deficits in both receptive and expressive language, have a significantly greater risk of later expressive language delays than do children with expressive language delays alone. Results from Lee's Developmental Sentence Scoring (DSS) (1974) were used to track the subject's expressive language abilities from the age of three through seven and analyzed using the Mann whitney sum of Ranks Test in each of the five years.

The research question asked was: Do children at twenty to thirty-four months of age with delays in both receptive and expressive language have a significantly higher risk of having language deficits at school age, than children at twenty to thirty-four months, with expressive delays alone.

To answer this question, raw scores of the DSS were ranked, summed, and compared between children with expressive language delays alone and children with both expressive and receptive delays. The Mann Whitney was used to determine whether significant differences existed between the two language diagnostic groups. DSS mean ranked scores are presented in Table II. 
TABLE II

DSS MEAN RANKS FOR SUBJECTS WITH DELAYS IN EXPRESSIVE LANGUAGE AND SUBJECTS WITH CONCOMITANT RECEPTIVE LANGUAGE DEFICITS

$\begin{array}{lll}\text { Year } & \begin{array}{l}\text { Subjects with } \\ \text { exp. delay }\end{array} & \begin{array}{l}\text { Subjects with } \\ \text { exp./rec. delay }\end{array} \\ \begin{array}{l}\mathrm{N}=19 \\ \text { Mean Rank }\end{array} & \begin{array}{l}\mathrm{N}=6 \\ \text { Mean Rank }\end{array} \\ 1988 & 14.34 & 8.75 \\ 1989 & 14.32 & 8.83 \\ 1990 & 14.32 & 8.83 \\ 1991 & 13.16 & 12.50 \\ 1992 & 12.84 & 13.50\end{array}$

Results of the Mann Whitney indicated that significant differences, using a .05 confidence level, do not exist between the two groups in any of the five targeted years (See Table III). The statistical results failed to reject the null hypothesis which stated that receptive language deficits at twenty to thirty-four months of age are not a possible predictor of lasting language deficits. This does not necessarily indicate that a relationship does not exist between the variables, only that there is insufficient evidence to conclude that a significant difference exists. 


\begin{tabular}{ccccc}
\hline \multicolumn{5}{c}{ TABLE III } \\
SUMMARY OF MANN WHITNEY SUM OF RANKS TEST \\
MEAN RANKS FOR SUBJECTS WITH EXPRESSIVE \\
LANGUAGE DELAY AND SUBJECTS WITH \\
CONCOMITANT RECEPTIVE DELAYS
\end{tabular}

When looking at the DSS scores for the total 25 subjects used in the study at ages three through seven, the percentage of scores above the tenth percentile (indicating the child is within normal range on the DSS) increased proportionately among groups from 1988 to 1994 (See Table IV). In fact at age seven, both groups had over $80 \%$ of their subjects outgrow their expressive language delay, possibly indicating that influences other than receptive language are contributing to the lasting deficits. 
TABLE IV

PERCENTAGE OF SUBJECTS CONSIDERED TO BE WITHIN NORMAL RANGE ON THE DSS

* numbers in ( ) refer to number of subjects Subjects with Subjects with

$\frac{\exp \text {. delay }}{\mathrm{N}=19} \quad \frac{\text { exp./rec. delay }}{\mathrm{N}=6} \frac{\text { Total }}{\mathrm{N}=25}$

$\begin{array}{lllllll}1988 & 638 & (12) & 33 \% & (2) & 568 & (14) \\ 1989 & 57 \% & (11) & 33 \% & (2) & 528 & (13) \\ 1990 & 788 & (15) & 678 & (4) & 768 & (19) \\ 1991 & 428 & (8) & 338 & (2) & 408 & (10) \\ 1992 & 898 & (17) & 838 & (5) & 888 & (22)\end{array}$

Scores above the 10 th percentile considered within the normal range

\section{DISCUSSION}

The data show that children with concurrent delays in expressive and receptive language do not perform significantly different on the DSS measure of expressive language when compared to subjects with expressive delays alone, over a five year period. The fact that this measure did not produce any significant differences among the two groups may be attributed to several factors including: (a) insignificant sample size, (b) the comparison of unmatched groups, (c) use of a higher than normal cutoff score when determining receptively delayed children, or (d) receptive language skills are not reliable predictors of the 
continuance of an expressive language delay in the school age child.

Insignificant Sample Size

The objective of the PLDP was not specifically for the purpose of comparing children's language outcomes within the categories of expressively delayed and expressivelyreceptively delayed. Therefore, the subjects who met the criteria for this particular study were only a small portion of the PLDP's total participants. Thirty-seven subjects were identified at intake; however, complete data was found on only 25 of the original 37 subjects. Nineteen of those children were considered to have deficits in expressive language, and six were determined to have concomitant receptive delays. Not only are the groups variable in terms of size, they are not matched for age, SES, or sex, and neither are of significant sample size for providing conclusive data.

High Cutoff Score for Determining Receptive Language Delays

As stated earlier, children determined to be delayed in receptive language for this study needed to fall more than one standard deviation below the mean on the RDLS. This cutoff point was used to allow for additional subjects in the receptively and expressively delayed group. If the accepted levels of determining a delay $(-1.5$ or -2.0 standard deviations below the mean) would have been used, the potential subjects in the receptive and expressive group 
would have been severely limited.

Using such a high cutoff value may have affected the results of the current study. One could argue that the children in the expressive/receptive delayed group did not have a true receptive delay. This in turn, would account for the insignificant results, if the two groups used in the study were actually more similar to each other than different.

Receptive Language as a Predictor of Language Abilities Another possible conclusion which can be drawn from this study is that receptive language scores are not an adequate predictor of later language abilities in the school age child. This can be evidenced not only by the insignificant statistics, but also by the percentage of subjects in both groups still delayed at age seven. If receptive language is truly not an adequate mark of severity and lasting language deficits, research may need to focus on other concurrent factors which may affect a child's language abilities. 


\section{CHAPTER V}

\section{SUMMARY AND IMPLICATIONS}

SUMMARY

Researchers in the field of language development have yet to find any conclusive data supporting differentiating outcomes for late talking toddlers. This often presents problems for pediatricians and speech-language pathologists when recommending intervention for young children who are slow in their development of expressive language. While receptive language abilities in these children have often been the focus in determining a language disorder's severity and thus the a child's prognosis, there has been much conflicting research, which questions the notion of receptive language as a predictor of outcome (Thal \& Tobias, 1994; Thal, Tobias, \& Morrison, 1991; Paul, Spangle-Looney, \& Dahm, 1991; Bishop \& Edmondson, 1987).

The purpose of the present study was to compare the expressive language outcomes of children with expressive delays to children with both expressive and receptive delays over a five year period. This research project looked at DSS scores in twenty-five subjects from the age of three through seven. The data was collected and analyzed using the Mann Whitney Sum of Ranks statistical analysis, to determine if significant differences existed between the two 
groups. No significant differences were found between the groups in any of the five years studied. These findings may indicate that receptive language abilities are not adequate indicators of language performance in the school age child. IMPLICATIONS

\section{Clinical Implications}

The results of this study indicate that there is insufficient evidence to suggest that receptive language deficits at twenty to thirty-four months are a possible factor of a lasting language deficit at school age. However, several clinical implications still exist, including: (a) counseling for parents, (b) preventative treatment programs, and (c) methods for treating a client.

Counseling for the parents. Regardless of the results of the present study, parents should be presented with all of the information relating to the likelihood of their child not outgrowing their language delay. Counseling from the SLP and information on the percentage of SELD children who have learning disabilities, will allow the parent to make informed decisions about beginning remediation programs for their child at a young age.

preventative treatment programs. If a predictive measure such as receptive language abilities can be found, treatment programs can begin with more certainty at a much younger age in children. Since this area of research, including the present study, still produces conflicting 
results, it is important to provide preventative treatment programs for all language and learning disordered children as early as possible. It is likely that $50 \%$ of these children will not outgrow their deficits (Paul, spangle Looney, \& Dahm, 1991; Whitehurst et al., 1991; Rescorla \& Schwartz, 1990; Scarborough \& Dobrich, 1990; Bishop \& Edmondson, 1987); therefore, preventative treatment is warranted.

Methods used in treating a client. This implication focuses on the fact that even if receptive language is not found as a predictor of later language deficits, it is an important piece of diagnostic information for the SLP. If a receptive and expressive delay exists together, treatment programs can be designed to encompass remediation procedures for one or all of the concomitant problems to meet the varied needs of the child in the areas of speech and language.

\section{Research Implications}

Future longitudinal research is necessary to better understand the effect of receptive language deficits on expressive language development. This research would need to include larger, properly matched groups, in order to provide more conclusive evidence to support or refute the assumptions made from the current and past research in this area.

Secondly, research might focus on one of the many other 
deficits which have been known to occur simultaneously with expressive delays, such as deficits in socialization skills or in narrative abilities. These factors may be found to be more accurate predictors of the language outcomes in late talkers. As Tallal (1988) stated, "until outcomes are understood, appropriate services cannot be provided." However, we can only understand these outcomes if we continue to research this area, and develop an understanding of what causes the deficits and an accurate prevalence of language disorders in the population (Tallal, 1988, p. 254). 
REFERENCES

American Psychiatric Association. (1994). Diagnostic and statistical manual of mental disorders: Fourth edition LDSM-IV. Washington: American Psychiatric Association.

Aram, D.M. (1988). Discussion. In J.K. Kavanagh \& T.J. Truss, Jr. (Eds.), Learning disabilities: Proceedings of the national conference (pp. 285-289). Maryland: York Press/Parkton.

Aram, D.M., Nation, J.E. (1975). Patterns of language behavior in children with developmental language disorders. Journal of Speech and Hearing Research, 18, 229-241.

Aram, D., \& Nation, J.E. (1980). Preschool language disorders and subsequent language and academic difficulties. Journal of Communication disorders, 13, 159170 .

Bayley, N. (1969). Scales of infant mental development. New York, NY: Psychological Corp.

Bishop, D., \& Edmondson, A. (1987). Language-impaired 4-year olds: Distinguish transient from persistent impairment. Journal of Speech and Hearing Disorders, 52, $156-173$

Doehring, D. (1988). Research strategies in human communication disorders. Austin, TX: Pro-ed. 
Haynes, C., \& Naidoo, S. (1991). Children with specific speech and lanquage impairment. Mac Keith Press: New York.

Lee, L. (1974). Developmental Sentence Analysis.

Northwestern University Press, Evanston, III.

Locke, J.I. (1994). Gradual emergence of developmental language disorders. Journal of Speech and Hearing Research, 37, 608-616.

Myers, J.K., \& Bean, I.I. (1968). A decade late: A follow-up of social class and mental illness. New York: Wiley \& Sons.

Paul, R. (1991). Profiles of toddlers with slow expressive language development. Topics in Language Disorders, 11(4), 1-13.

Paul, R., Laszlo, C., MCFarland, L, \& Midford, N. (1992). Language outcomes in late-talkers: Kindergarten. Portland State University, Department of Speech Communication.

Paul, R., \& Smith, R. (1993). Narrative skill in 4-year olds with normal, impaired, and late developing language. Journal of Speech and Hearing Research, 36, 858-865.

Paul, R., Spangle Looney, S., \& Dahm, P. (1991). Communication and socialization skills at ages 2 and 3 in "late-talking" young children. Journal of Speech and Hearing Research, $34,858-865$.

Rapin, I. (1988). Discussion. In J.K. Kavanagh \& T.J. Truss, Jr. (Eds.), Learning disabilities: Proceedings of the 
national conference (pp. 273-280). Maryland: York Press/Parkton.

Rescorla, I. (1989). The language development survey: A screening tool for language delay in toddlers. Journal of Speech and Hearing Disorders, 54, 587-599.

Rescorla, L., \& Schwartz, E. (1990). Outcome of toddlers with specific expressive language delay. Applied Psycholinguistics, 11, 393-407.

Reynel1, J. (1983). Developmental Language Scale. London: NEER Nelson.

Rutter, M. Mahwood, I. \& Howlin, P. (1992). Language delay and social development. In P. Fletcher, \& D. Hall (Eds.), Specific speech and language disorders in chilaren: Correlates, characteristics and outcomes (pp. 63-78). San Diego: Singular Publishing Group.

Scarborough, H., \& Dobrich, W. (1990). Development of children with early language delay. Journal of Speech and Hearing Research, 33, 70-83.

Schery, T. (1985). Correlates of language development in language-disordered children. Journal of Speech and Hearing Disorders, 50, 73-83.

Tallal, P. (1988). Developmental language disorders. In J.K. Kavanagh \& T.J. Truss, Jr. (Eds.), Learning disabilities: Proceedings of the national conference (pp. 181-272). Maryland: York Press/Parkton. 
Thal, D., \& Tobias, S. (1992). Communicative gestures in children with delayed onset of expressive vocabulary. Journal of Speech and Hearing Research, 35, 1281-1289.

Thal, D., \& Tobias, S. (1994). Relationships between language and gesture in normally developing and latetalking toddlers. Journal of Speech and Hearing Research, 37, $157-170$.

Thal, D., Tobias, S., \& Morrison, D. (1991) Language and gesture in late talkers: A 1-year follow up. Journal of Speech and Hearing Research, 34, 604-612.

Whitehurst, G., Fischel, J., Lonigan, C., ValdezMenchaca, M., Arnold, D., \& Smith, M. (1991). Treatment of early expressive language delay: If, when, and how. Topics in Language Disorders, $11(4), 55-68$.

Wolfus, B., Moscovitch, M., \& KinsBourne, M. (1980). Subgroups of developmental language impairment. Brain and Language, 10, 152-171. 
APPENDIX A

HUMAN SUBJECTS APPROVAL 


\section{OFFICE OF GRADUATE STUDIES AND RESEARCH}

Research and Sponsored Projects

\section{DATE: $\quad$ May 18th 1995}

TO: $\quad$ Traci Giacchero $\quad$ SSN\# 542-02-6687

FROM: For Laurie Skokan, Chair, HSRRC, 1994-95 $\begin{aligned} & \text { HSRRC Waived Review of Your Application titied "Effects of Receptive } \\ & \text { Language Deficits on Persisting Expressive Language Delays" }\end{aligned}$

lour proposal is excmpt from further HSRRC review, and you may proceed with the study.

Even with the exemption above, it was necessary by University policy for you to notify this Conmittee of the Proposed research and we appreciate your timely attention to this matter. If you makic changes in your research protocol, the Committee must be notified. This approval is valid for one year from date of issue.

c: Maureen Or Eldred

Rhea Paul, Project Advisor 
APPENDIX B

RAW DATA FROM DSS

YEARS 1988-1992 


\section{RAW DATA FROM DSS}

\begin{tabular}{|c|c|c|c|c|c|c|}
\hline $\begin{array}{l}\text { GROUP } 1 \text { - } \\
\text { GROUP } 2 \text { - }\end{array}$ & EXPRESSIVE & $\begin{array}{r}D E L A Y \\
/ R E C E F\end{array}$ & TIVE DI & SLAYED & & \\
\hline$\frac{\text { SUBUECT \# }}{12}$ & $\frac{\text { GROUP }}{1}$ & $\frac{1988}{2.80}$ & $\begin{array}{l}\text { DSS SC } \\
\frac{1989}{5.20}\end{array}$ & $\begin{array}{l}\text { CORES } \\
\frac{1990}{7.44}\end{array}$ & $\frac{1991}{7.14}$ & $\frac{1992}{8.52}$ \\
\hline 19 & 1 & 4.52 & 6.78 & 8.11 & 6.98 & 6.91 \\
\hline 57 & 1 & 5.16 & 8.22 & 6.82 & 7.88 & 9.94 \\
\hline 86 & 1 & 2.94 & 7.02 & 6.87 & 7.02 & 8.22 \\
\hline 87 & 1 & 4.96 & 7.90 & 8.96 & 8.24 & 8.66 \\
\hline 92 & 1 & 6.52 & 4.10 & 7.38 & 8.32 & 12.24 \\
\hline 94 & 1 & 0.00 & 2.91 & 6.06 & 5.00 & 9.88 \\
\hline 97 & 1 & 2.21 & 3.48 & 4.46 & 6.72 & 6.96 \\
\hline 98 & 1 & 5.56 & 6.90 & 6.82 & 6.42 & 8.84 \\
\hline 100 & 1 & 0.00 & 7.40 & 6.23 & 6.26 & 11.96 \\
\hline 102 & 1 & 4.35 & 8.08 & 7.98 & 7.58 & 9.84 \\
\hline 103 & 1 & 0.00 & 7.40 & 7.40 & 0.00 & 10.54 \\
\hline 105 & 1 & 4.80 & 6.68 & 9.06 & 10.26 & 10.24 \\
\hline 107 & 1 & 4.08 & 4.68 & 8.50 & 8.62 & 9.90 \\
\hline 109 & 1 & 7.04 & 10.85 & 6.78 & 7.02 & 9.14 \\
\hline 111 & 1 & 4.00 & 5.70 & 7.44 & 6.34 & 9.84 \\
\hline 114 & 1 & 2.05 & 6.74 & 11.16 & 7.94 & 12.04 \\
\hline 119 & 1 & 4.66 & 5.26 & 6.86 & 7.92 & 10.14 \\
\hline 142 & 1 & 7.02 & 4.56 & 6.30 & 6.66 & 9.31 \\
\hline 006 & 2 & 3.74 & 6.60 & 5.94 & 7.28 & 10.98 \\
\hline 007 & 2 & 2.82 & 6.44 & 6.74 & 9.07 & 10.26 \\
\hline 029 & 2 & 0.43 & 4.24 & 6.62 & 5.38 & 9.40 \\
\hline 085 & 2 & 4.12 & 5.63 & 5.82 & 7.28 & 10.08 \\
\hline 093 & 2 & 0.00 & 3.26 & 6.68 & 4.53 & 6.84 \\
\hline 122 & 2 & 2.53 & 5.00 & 10.28 & 7.18 & 9.46 \\
\hline
\end{tabular}




\section{APPENDIX C}

REYNELL DEVELOPMENTAL LANGUAGE SCALE

Reynell, J. (1983). Developmental language scale.

London: NFER Nelson 


\section{Rejunell Developmental Language: Scales \\ (Revised Edition) \\ Record Form}

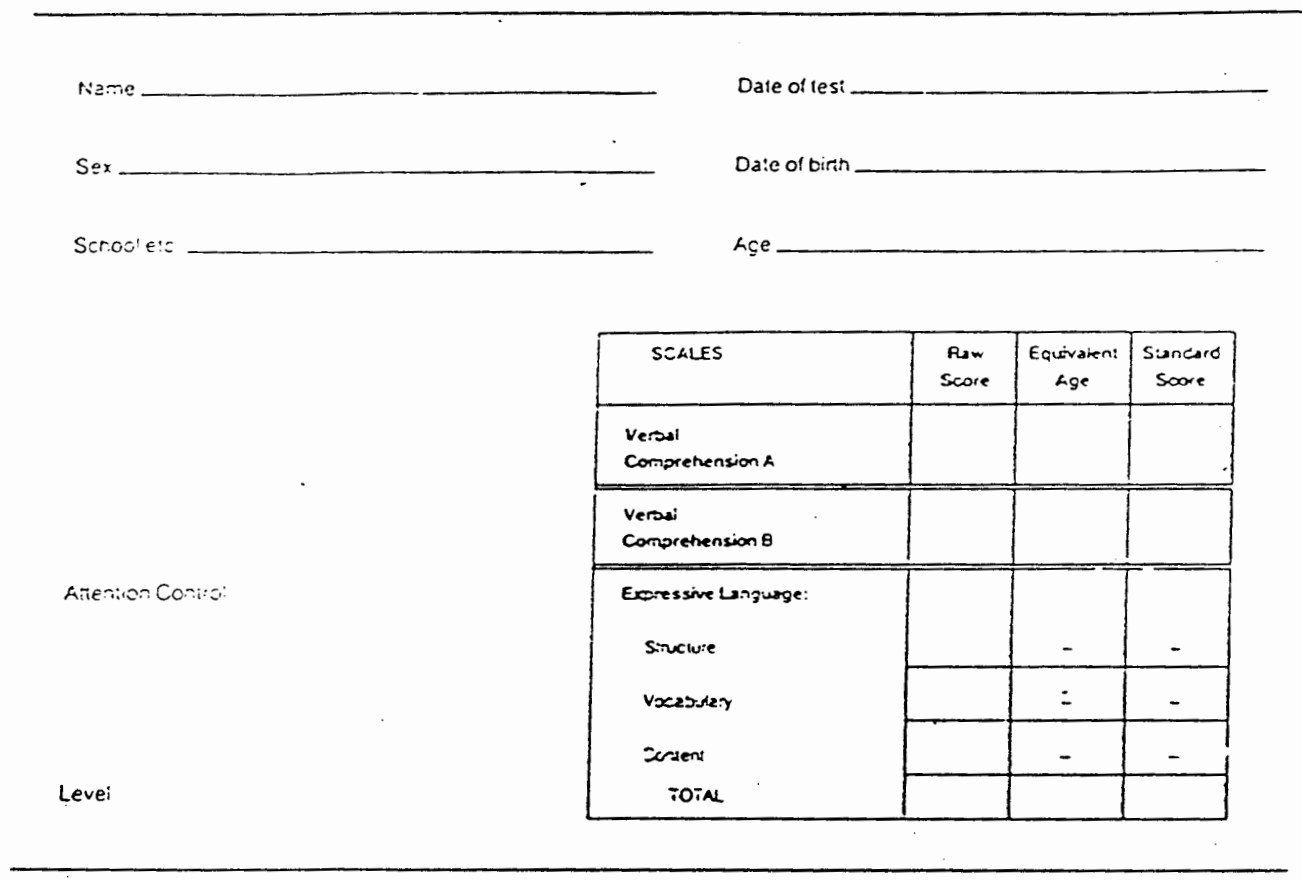

Commenis 
Verbal Comprehension Scale A

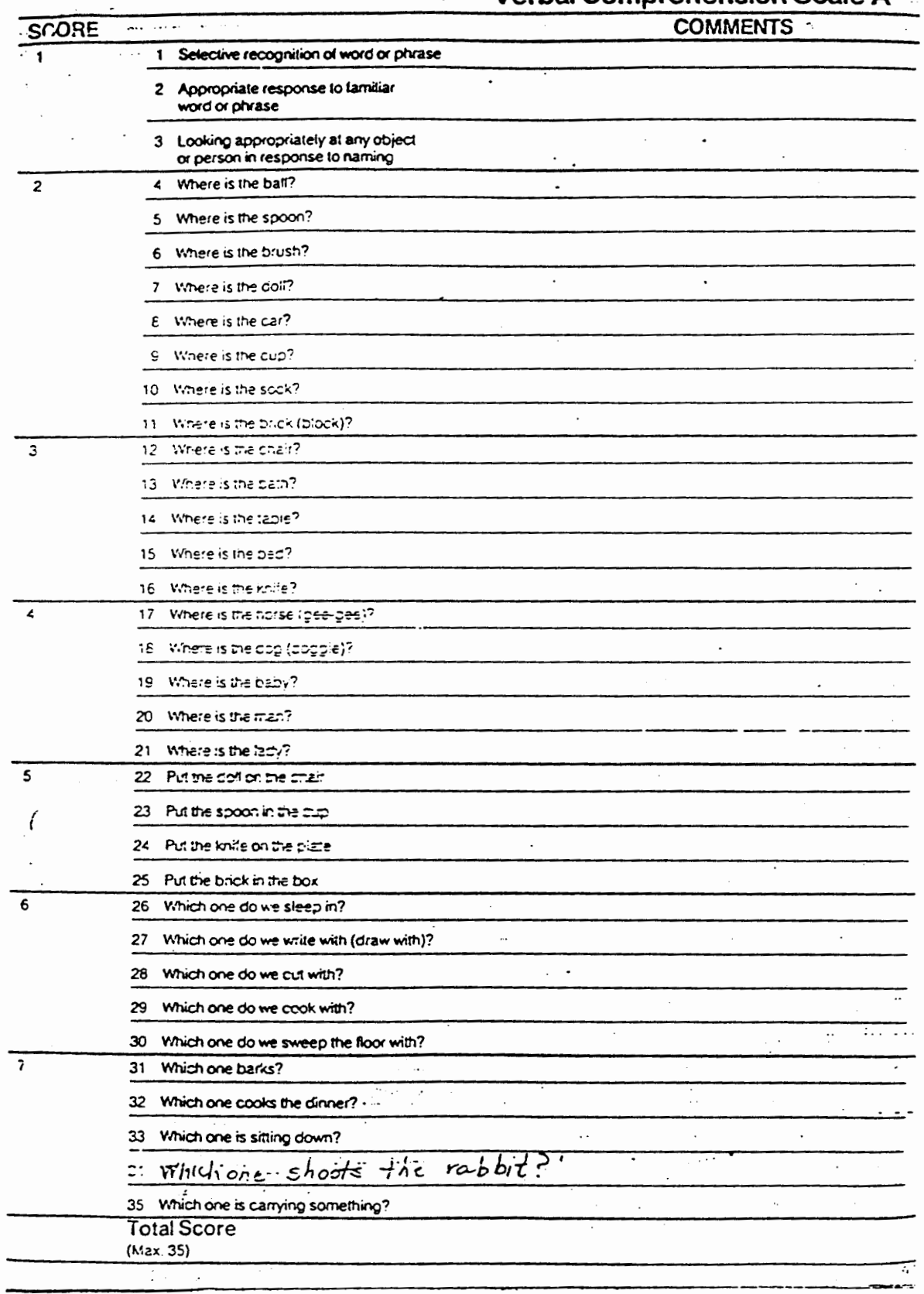


Verbal Comprehension Scale. A

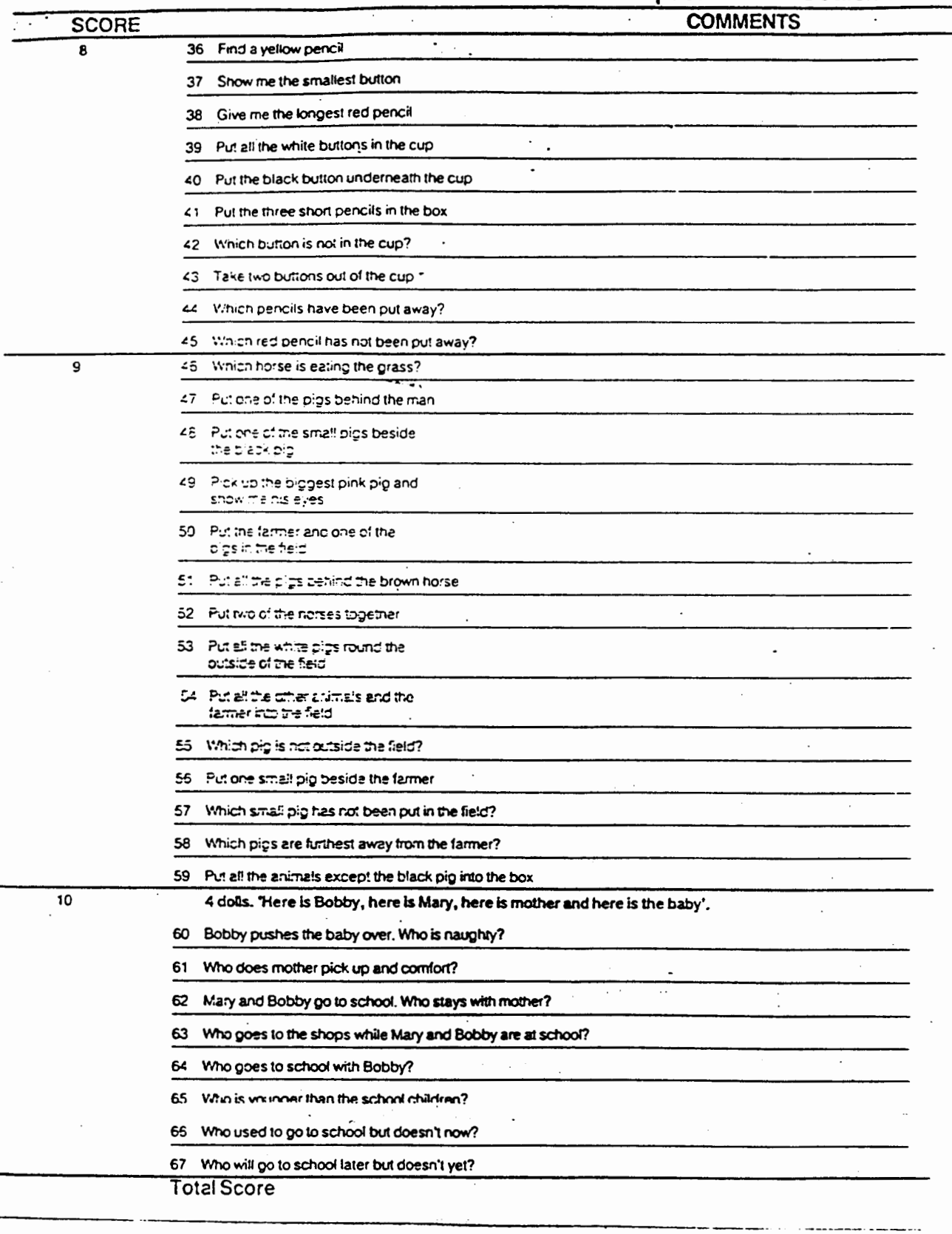


APPENDIX D

REYNELL DEVELOPMENTAL LANGUAGE SCALE

STANDARD SCORES

Reynell, J. (1983). Developmental language scale.

London: NFER Nelson 


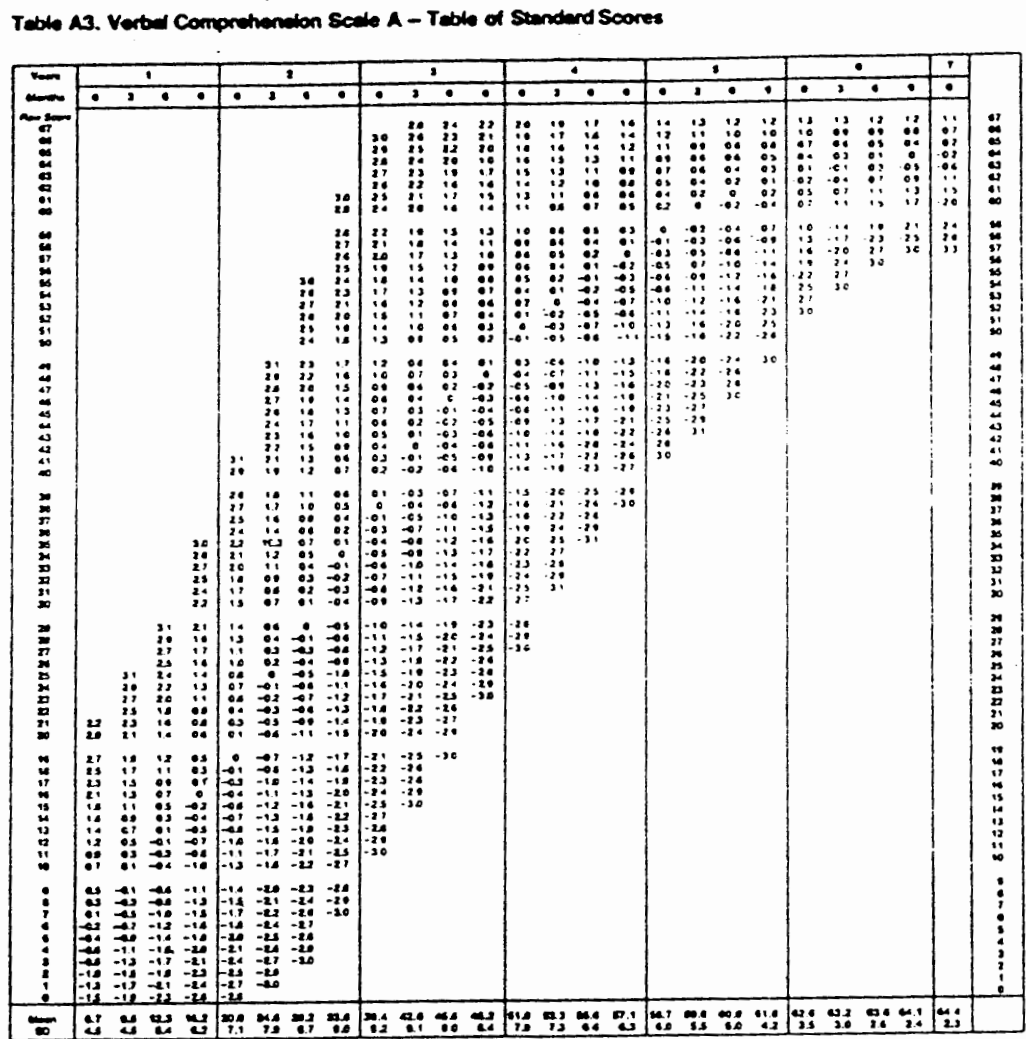




\section{APPENDIX E}

DEVELOPMENTAL SENTENCE SCORE:

SCORING CRITERIA

Lee, L. (1974). Developmental sentence analysis. Evanston, IL: Northwestern University Press. 


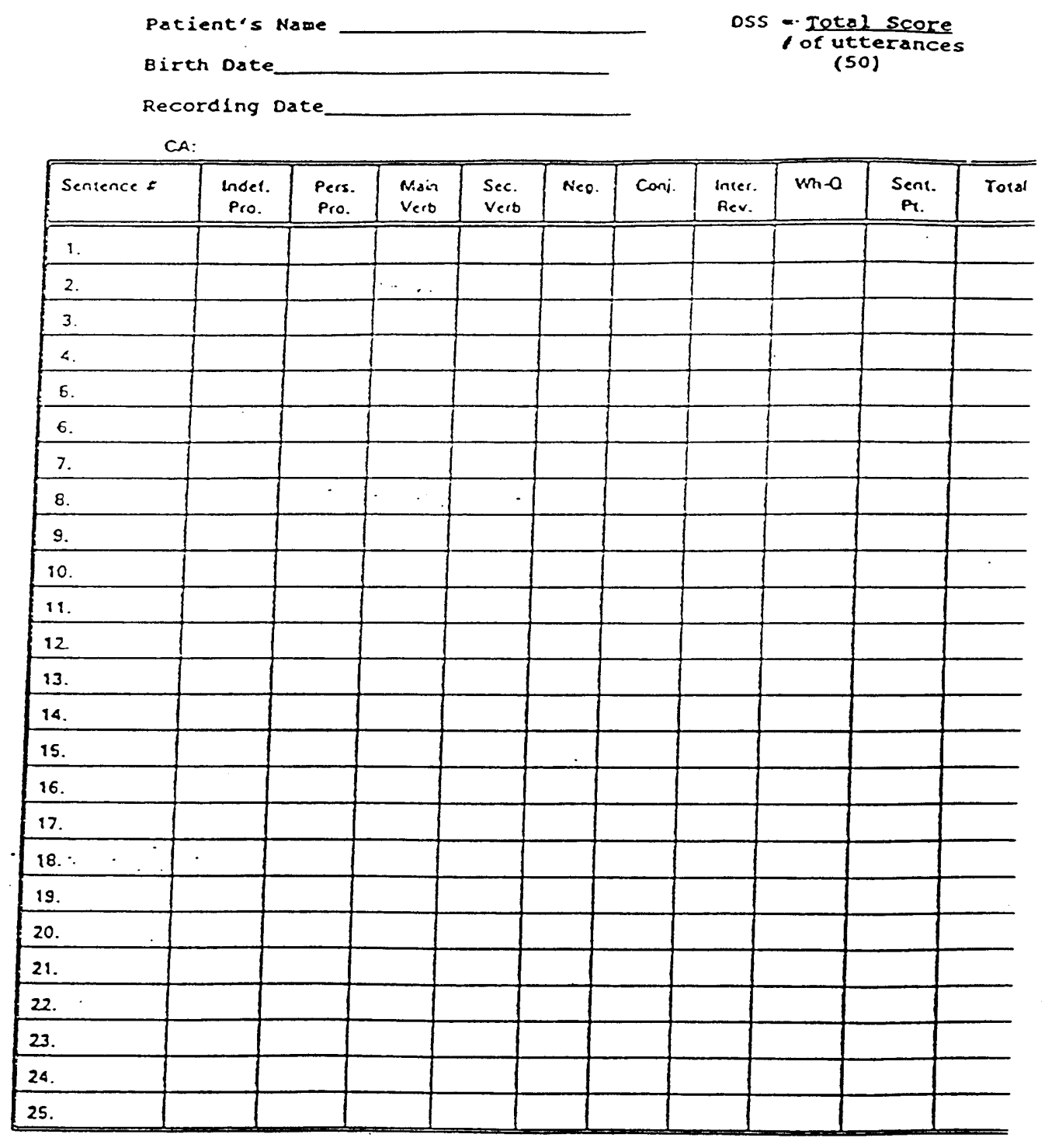




\begin{tabular}{|c|c|c|c|c|c|c|c|c|}
\hline & 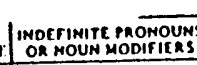 & 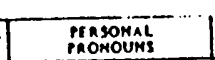 & MAIN VERES & sccondaAr veness. & Xtcailives & | cosilycrioys & 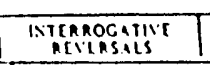 & NHoctsrions \\
\hline 1 & 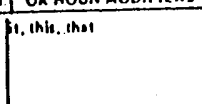 & 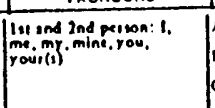 & 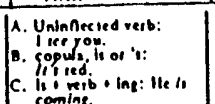 & & 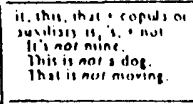 & $T$ & 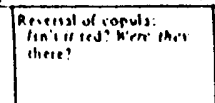 & \\
\hline 2 & & 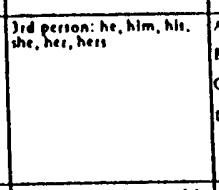 & 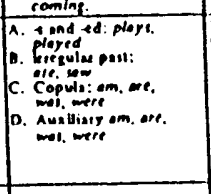 & 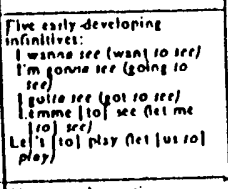 & & 1 & & 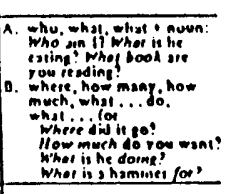 \\
\hline 3 & 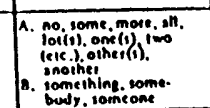 & 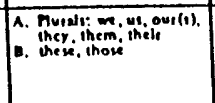 & & 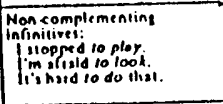 & - & ind & & \\
\hline 4 & 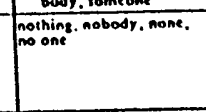 & & 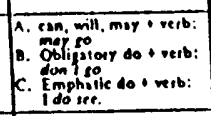 & 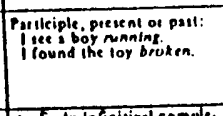 & tinitan & & 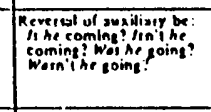 & \\
\hline 5 & & 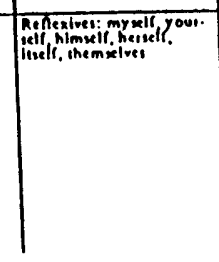 & & 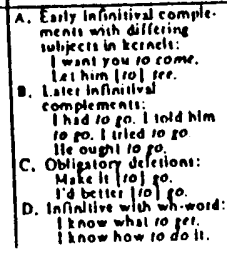 & & 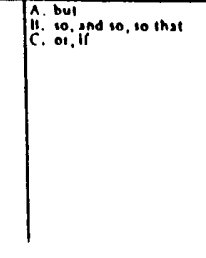 & & 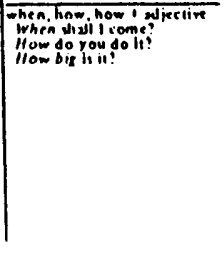 \\
\hline
\end{tabular}




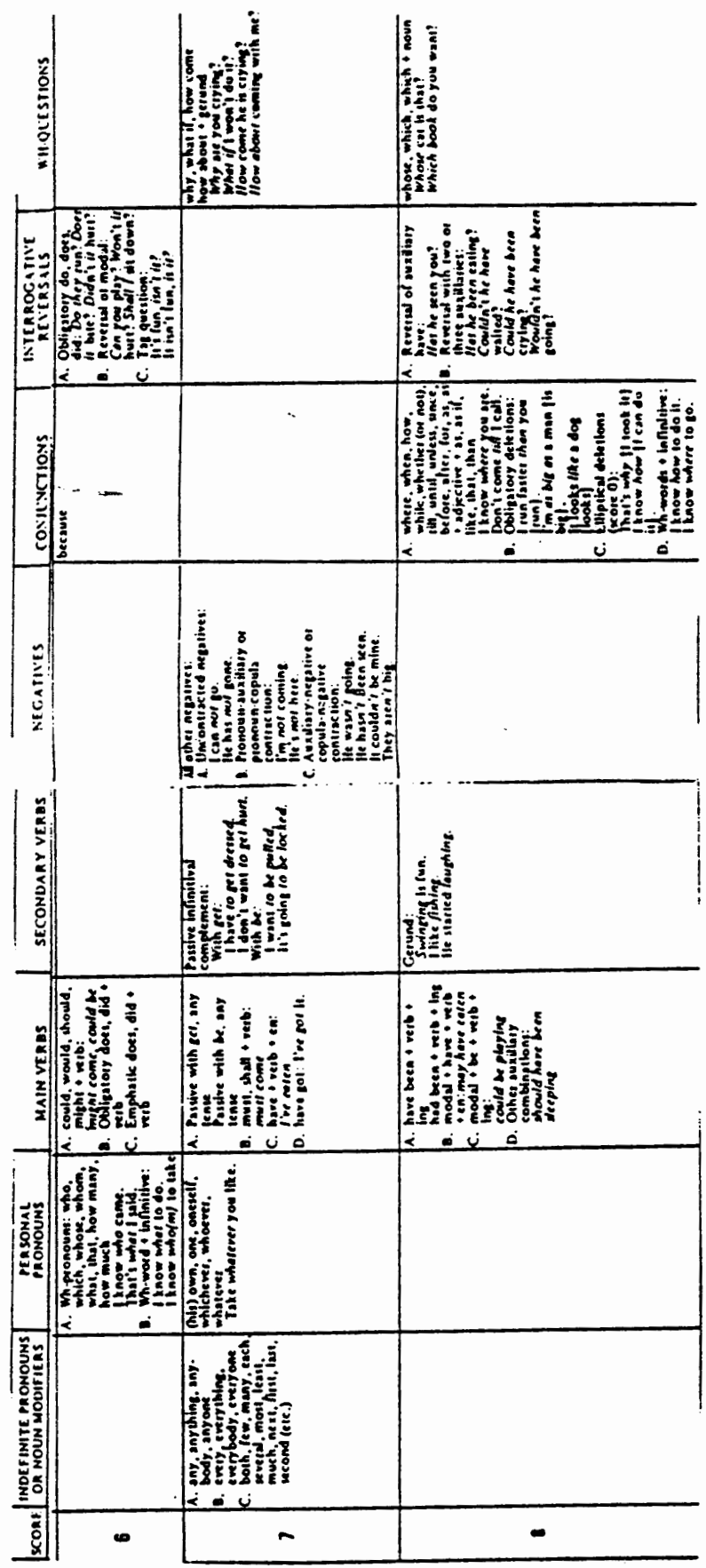


APPENDIX F

DEVELOPMENTAL SENTENCE SCORE:

NORMS

Lee, L. (1974). Developmental sentence analysis. Evanston, IL: Northwestern University Press. 
56

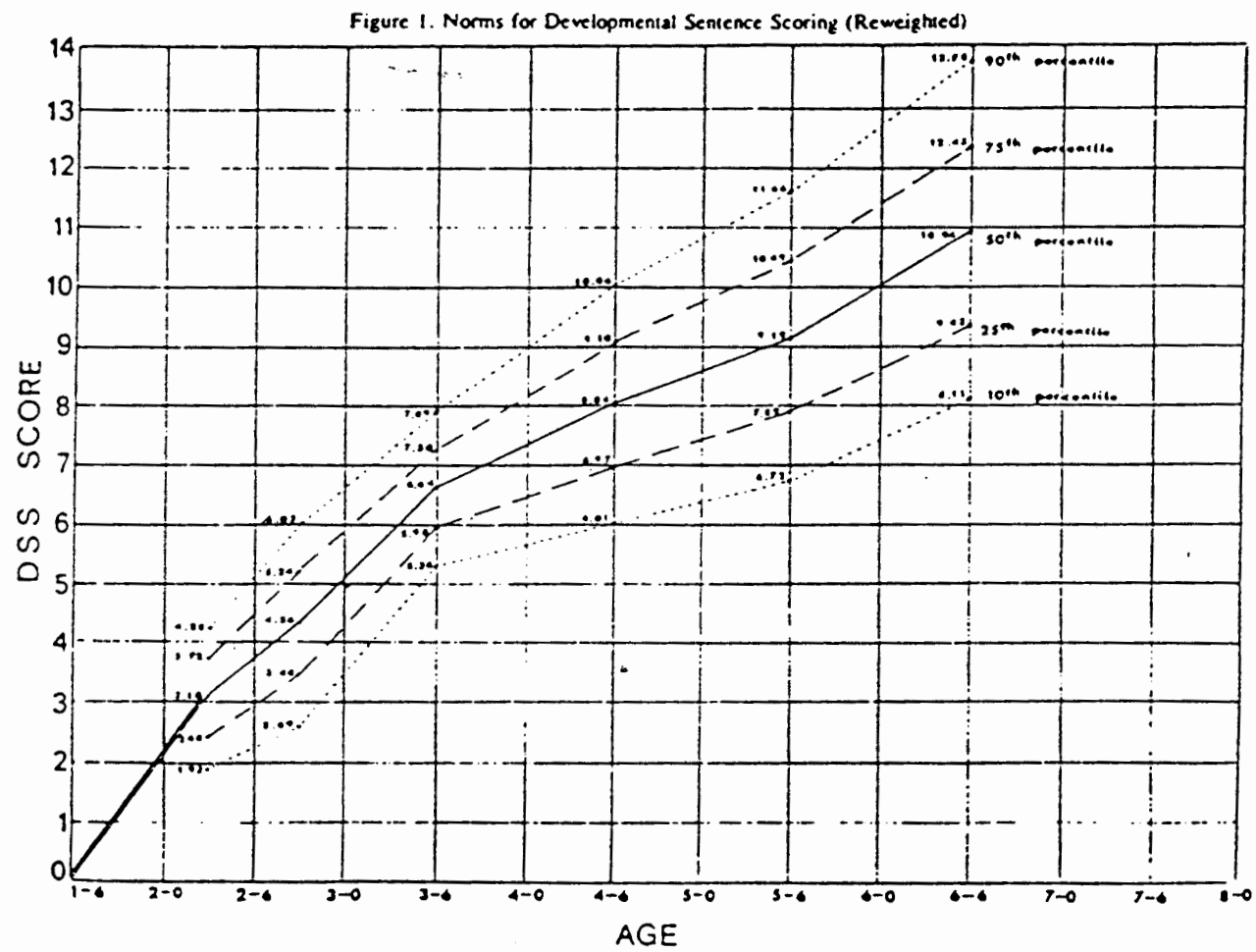

